Gender, Place \& Culture

A Journal of Feminist Geography

ISSN: 0966-369X (Print) 1360-0524 (Online) Journal homepage: https://www.tandfonline.com/loi/cgpc20

\title{
Globalising myths of survival: post-disaster households after Typhoon Haiyan
}

\section{Yvonne Su \& Maria Tanyag}

To cite this article: Yvonne Su \& Maria Tanyag (2019): Globalising myths of survival: post-disaster households after Typhoon Haiyan, Gender, Place \& Culture, DOI: 10.1080/0966369X.2019.1635997

To link to this article: https://doi.org/10.1080/0966369X.2019.1635997

曲 Published online: 15 Jul 2019.

Submit your article to this journal $\widetilde{T}$

山 Article views: 355

Q View related articles $\widetilde{ }$

View Crossmark data $\nearrow$ 


\title{
Globalising myths of survival: post-disaster households after Typhoon Haiyan
}

\author{
Yvonne Su a and Maria Tanyag ${ }^{\mathrm{b}, \mathrm{c}}$ \\ ${ }^{a}$ Department of Political Science, University of Guelph, Guelph, Canada; ${ }^{b}$ Department of \\ International Relations, The Australian National University, Canberra, Australia; \\ 'Gender, Peace and Security Centre, Monash University, Victoria, Australia
}

\begin{abstract}
Disasters, as forms of crisis, offer opportunities to place in sharper focus historical and ongoing inequalities in the production and reproduction of everyday life. The opportunity for transformative change, however, risks being lost when representations of disaster increasingly obscure and silence the full costs and complexity of post-disaster recovery. This article identifies the construction and subsequent proliferation of survival myths in the context of the Philippines after the 2013 Typhoon Haiyan disaster from a feminist perspective. Using data from in-depth interviews and surveys, we examine the experiences of middle and lower-class households in three heavily affected communities in Tacloban City to challenge three dominant survival myths: the local culture of mutual assistance (bayanihan), the endless resourcefulness of Filipinos in times of crisis, and the positive contributions of overseas migrant remittances. We argue that these myths have served as tools for reinforcing gendered inequalities during and after the disaster because they render invisible the feminisation of care burdens, and contribute to gender gaps in ensuring accountability for post-disaster governance. The evidence from this research underscores the importance of interrogating how similar survival myths are being globalised in disaster governance at the expense of forging substantive gender equality in post-disaster settings.
\end{abstract}

\section{ARTICLE HISTORY}

Received 16 August 2018

Accepted 11 June 2019

\section{KEYWORDS}

Climate change; disasters; gender and crisis; Philippines; resilience

\section{Introduction}

Disasters, as forms of crisis, offer opportunities to place in sharper focus historical and ongoing inequalities in the production and reproduction of everyday life (Katz 2008; Enarson 2012; Bradshaw 2015). The opportunity for transformative change, however, risks being lost when representations of disaster increasingly obscure and silence the full costs and complexity of 
post-disaster recovery. This is because disasters continue to be framed within binary narratives - victim/survivor, vulnerability/resilience, and devastation/ rebuilding (Arora-Jonsson 2011; Bradshaw 2015; Smyth and Sweetman 2015). At the global level, disasters have been represented and viewed through a Western-centric or Global North vantage point. In practice, this is evident in the emphasis placed on conditions that make disasters exceptional to the point where the spectacle of the crisis overshadows a continuum of other forms of insecurities (Gaillard et al. 2017, 429; Gaillard, Gorman-Murray, and Fordham 2017). Yet for the Global South, the disproportionate burden of climate change impacts such as extreme weather events have long intersected with routine poverty and marginalisation albeit now with increasing frequency (Eckstein, Künzel, and Schäfer 2017). Indeed for the Warays, an ethnolinguistic group who have traditionally resided among the most disaster-prone and less developed areas in the Philippines, "Kada adlaw baga hin kalamidad para ha mga pobre" [Every day is like a calamity for the poor]' (Su and Mangada 2018, 68, emphasis added).

This article identifies the construction and subsequent proliferation of survival myths by both national and international actors from the global Typhoon Haiyan response, a post-disaster case study in the Philippines. Haiyan, then the strongest storm to ever make landfall, devastated the Philippines on 8 November 2013. The disaster, locally known as 'Yolanda', caused widespread destruction in the whole country, but the worst and unprecedented impacts occurred in the Eastern Visayas region. There were reportedly 6,300 deaths, 1.1 million houses damaged or destroyed, and over 4 million people internally displaced (UNGA 2016, 5). In the aftermath, '[t]he extent of the destruction was such that the international humanitarian system declared it a Level 3 emergency, the first time this mechanism had been engaged in the context of a natural disaster'. A Level 3 emergency is activated by the Inter-Agency Standing Committee (IASC) for what are considered as the most complex and challenging humanitarian emergencies. This emergency response category means 'an enhanced level of mobilization of resources, funding, logistics and coordination above that normally deployed and the ability to draw on additional global resources' (UNGA 2016, 5).

Because the disaster caused by Haiyan was both sudden and immense, this was matched by an equally high outpouring of humanitarian assistance. Haiyan-affected communities were subsequently inundated by a motley collection of government assistance and humanitarian aid, as well as military contingents that responded to the disaster. The Haiyan response mobilised aid from fifty-seven countries, twenty-nine foreign military contingents, United Nations agencies, and local and international non-governmental organisations (NGOs) (Mangada 2016; Tanyag 2018). Moreover, according to Oxfam $(2013,7)$, '[w]ithin the first three weeks of the response, $\$ 391 \mathrm{~m}$ in 
humanitarian assistance was given, with the largest contributions from the UK, the US, Japan, Australia, Canada, Sweden, the United Arab Emirates, the Netherlands and Saudi Arabia'. The impact was visibly drastic such that a female NGO informant who has served communities for more than twenty years emphatically commented, international NGOs 'are changing Visayas' landscape' (personal interview, Tacloban City, 24 February 2015).

We identify and challenge three dominant survival myths in the aftermath of this historic case: the local culture of mutual assistance (bayanihan), the endless resourcefulness of Filipinos in times of crisis, and the positive contributions of overseas migrant remittances. Immediately after the disaster, state and non-state actors relied on and co-constructed stories of devastation and death as part of the disaster response. The disaster response also eventually turned to stories of survival that served as the galvanising 'brand' of recovery efforts. It is important to bring such stories to the surface to uplift the morale of both affected communities and responders in times of crisis. We question, however, the vested interests that might inform the over-deployment of specific narratives in the aftermath of a disaster. Building on critical and feminist scholarship on gender and disasters, we examine myth deployments with a specific focus on the intersections of gender and class hierarchies. How have gender and class dynamics at the household level shaped daily survival after Haiyan contrary to dominant survival myths? To what extent do survival myths surrounding the post-disaster household inform national and global myths about post-disaster resilience?

Feminist research has shown that disasters are gendered because they occur within geographies of unequal resource allocation between men and women, gender-differentiated institutional and political responses, and cultural and religious expectations that influence experiences in the immediate aftermath and long-term recovery phases (Enarson 1998; Bradshaw 2015; Tanyag 2018). In addition, how gender is incorporated and translated in the practice of disaster governance needs to be scrutinised because 'there is a danger of oversimplifying how gender shapes responses to disaster or is responsible for generating certain kinds of vulnerabilities or strengths' (Cupples 2007, 155). Positive strides have been made in recognising the importance of employing a gender lens for research and policymaking on disasters (Bradshaw 2015, S62; Enarson 2012) and environmental issues over the last four decades (Arora-Jonsson 2014). However, gender research 'appears to have had a marginal effect on environmental practice on the ground,' and that 'the link between research and every day work appears to be more elusive' (Arora-Jonsson 2014, 296).

One key barrier is that international and national policies, such as the Hyogo Framework for Action and the Sendai Framework for Disaster Risk Reduction, still omit or fall short in addressing nuances in the vulnerabilities 
resulting from multiple and intersecting structures of power shaped by gender, class, sexuality, ethnicity and citizenship, religion, geographic location, disability and age (Gaillard, Gorman-Murray, and Fordham 2017, 19; PereraMubarak 2013). In addition, disasters run the risk of being depoliticised through the growth in the use of "resilience" as a discourse deployed to divest state responsibilities on preparedness, mitigation and response onto individuals and communities (Tanyag 2018, 569). Yet, gender relations mean that how these responsibilities are brokered at household and community levels may be profoundly unequal. Therefore, a necessary step in ensuring that gender research translates into policies and interventions that actually promote the well-being of all members of society during and after crises is by challenging universalizing narratives, one form of which includes myths of survival. Questioning the underlying motives to and implications of survival myths is vital first, in ensuring ongoing accountability for post-disaster governance such that national and global responders actually address the needs of affected communities. Second, so that a comprehensive understanding of issues arising in the aftermath of a disaster can not only effectively be used to inform subsequent disaster response, but also help usher in a more gender-equal post-disaster recovery and societal transformation.

This article has three parts. First, we situate the globalised impacts of survival myths on humanitarian and development agendas by engaging with a growing body of critical research on gender and disasters. Second, we examine the three myths of survival based on our evidence from post-Haiyan Philippines within one specific geographic site of Tacloban City. We argue that survival myths ultimately do more harm than good when they preclude the identification of specific conditions that render households and communities vulnerable to disasters, as well as the tremendous gendered inequalities that are often exacerbated after disasters. They foreclose spaces that can leverage disasters into fundamentally remaking 'the material social practices of everyday life in ways that alter our collective expectations of ourselves and the social forms and institutions through which we both make our lives and make them sensible' (Katz 2008, 18). Third and finally, conclusions drawn from our research underscore the need for continued vigilance by means of feminist-informed, evidence-based disaster research.

\section{Globalising survival myths}

Myth-making is an increasingly globalised political process. A propensity in the circulation or 'tyranny' of myths has been named and critiqued in the context of international development and environmental practice (Kothari 2001; Guijt and Shah 1998; Doss et al. 2018). For instance, De La Rocha (2007, 45) identifies, 'a powerful myth that has spread throughout 
international development agencies: that poor households are able to survive in spite of macroeconomic policies that foster unemployment, increase poverty and decrease the amount of resources in the hands of the poor'. The myth of survival emphasises adaptation, solidarity, and reciprocity as the major strategies for surviving poverty. De La Rocha (2007) further outlines two main dimensions of this myth: that the poor are resourceful, and that this resourcefulness particularly in the hands of the poor is plentiful. The first dimension describes the endless capacity of the poor to work, to consume less, and to be part of mutual help networks as traits of resourcefulness that help them survive. The second is that the poor have a wide variety of tangible and intangible individual and social resources that they can easily maximise and take advantage of. Since mutual support systems are inherent parts of society, it is assumed that they can provide safety nets for the poor to achieve survival. And yet, an increasing reliance and pressure on kinship ties and community support in the absence of state contributions to replenish social support systems inevitably leads to the very erosion of mutual help, solidarity, and social exchange (De La Rocha 2007, 47). These safety nets are typically assumed limitless and readily harnessed without regard for what range of costs their maintenance entails especially for women and girls (Elson 2010).

Survival myths recur in the context of disasters and they require a feminist analysis to reveal how they may serve as tools for reinforcing gendered inequalities during and after the disaster. First, Arora-Jonsson (2011) argues that dominant discourses on climate change rely on and help promote generalisations of women from the Global South, portraying them as either virtuous or vulnerable. However, these stereotypes 'can deflect attention from power relations and inequalities reproduced in institutions at all levels and in discourses on climate change. This focus can lead to an increase in women's responsibility without corresponding rewards' (Arora-Jonsson 2011, 745). In the post-Haiyan case, survival myths obscure the gender relations that operate before, during and after disasters. According to a female NGO worker, 'humanitarian mindset is still that gender must come later ... much later in emergency settings. The focus is really more on the façade ... just the physical rebuilding' (personal interview, Guiuan, Samar, 24 February 2015). Yet, when we challenge survival myths, gender is not separate from the political economy of disaster response (Katz 2008; Bradshaw 2015). For instance, when the focus of crisis resource allocation prioritises physical rebuilding or restoration of order, this is supported by the tacit reliance on personal sacrifices made by frontline social workers helping communities rebuild in less visible aspects such as emotional and psychological well-being (Tanyag 2018, 570).

A feminisation of responsibility and obligation results when the distinct long-term harms, such as the multiple care burdens borne distinctly by 
women and girls, are obscured in disaster response (Tanyag 2018). Global and national development programs have been critiqued for reproducing assumptions regarding women's innate selflessness resulting from their biological and social roles as mothers (Brickell and Chant 2010). Especially in times of crisis, women are targeted as key agents in interventions because they are believed to be selfless by nature and therefore will create more impact for programs (Bradshaw 2015, S69; Arora-Jonsson 2011). Consequently, the valorisation of women's altruism 'act mainly to intensify gender-differentiated altruism rather than redress it' (Brickell and Chant 2010, 156) because they allow for the increase in responsibilities added to women without redistributing roles in the household and community. Yet, it is through a gendered division of labour that women are often most obligated in providing and receiving social support due to their caregiving roles beginning at the household level (Perera-Mubarak 2013; Bradshaw 2015; Tanyag 2018). Women's care labour at home and volunteer roles in community welfare are taken for granted as evidenced by the absence of critical inflows needed to sustain their labour (Elson 2010; Tanyag 2018). Indeed, as Elson $(2010,208)$ points out, '[c]ommunities may respond to the crisis through an increase in organised volunteer work, for both self-help, and to help those hardest hit ... [but] ... The crisis may reduce the provision of such support, at a time when the demand for support is growing'.

Myths can develop because rendering visible how disasters intensify women's burdens and insecurities requires much more than measures that rely on women to speak up. For instance, 'participation' is now the orthodoxy in disaster resilience policies and programming with the widespread uptake of community-based, participatory, or bottom-up approaches in development and humanitarian frameworks in general (Guijt and Shah 1998; De La Rocha 2007). In practice such approaches, however, reflect a tendency to homogenise interests and experiences by similarly reproducing myths about the community. Feminist research has drawn attention to hidden inequalities including violence perpetrated within households and communities, and internalised barriers by women that prevent them from full participation such as taking on leadership roles (Smyth and Sweetman 2015, 407). As Kothari $(2001,151)$ cautions us, the 'tyranny of participation' in post-disaster contexts may come at the expense of accounting for 'the capacity of individuals and groups to resist inclusion, resist projections about their lives, retain information, knowledge and values, and act out a performance and in so doing present themselves in a variety of ways'. Thus, we need better analytical tools to understand the complex relationships in disaster response between humanitarian responders and affected communities. Second, the power of survival myths is that the repetition of essentialised representations over time can undermine the ability of men and women to make demands from and hold both governments and international donor organisations 
accountable (Horton 2012, 297). This is relevant in the case of Tacloban where the disaster exposed affected communities to extreme dependence on humanitarian assistance. Their vulnerable status pushed the people to the point where they felt 'obliged to be grateful' no matter what type of assistance they received and regardless of whether the assistance met their real needs or concerns (Ong, Flores, and Combinido 2015; Sherwood et al. 2015). Furthermore, in the aftermath of Haiyan, Ong, Flores, and Combinido (2015, 8) point out this sense of indebtedness or 'utang na loob' was particularly strong among affected communities such that:

There is therefore a natural disincentive for many people to express criticism in agencies' feedback mechanisms, as people observe that humanitarians have no 'natural obligation' to help, especially as they come from overseas. This is compounded by local expectations to demonstrate hospitality to foreign workers, as shaped by the Philippines' long history of colonialism and 'white love'.

International responders reportedly noted how the Filipinos were the 'happiest beneficiaries they have seen' yet they 'struggled to recognise and respond to the deep discontent that often exists alongside gratitude and optimism' (Sherwood et al. 2015, 28). As we discuss further below, culturally sanctioned gratitude and severe economic dependence are gendered in that they exacerbate the inability of women and girls to complain against cases of sexual and gender-based violence linked to the large-scale deployment of foreign and national military troops in the affected areas (see also Tanyag 2018, 575).

In the case of Haiyan, survival myths eclipsed on-the-ground accounts and subsequent research studies that have revealed shortcomings in the disaster response. Long after the disaster struck, communities suffered compounded violence, danger, and losses due to these failings (IBON Foundation, Inc. 2015; Oxfam 2015; DSWD et al. 2014). Indeed, five years after the disaster there are now worrying signs that survival myths are reconstructing reality for Tacloban City. For example, a recent online tourism campaign from the local government of Tacloban branded the city 'home of the happiest people in the world' (Su, Mangada, and Turalba 2018). The tourism campaign video was shared widely on social media and was clearly targeted to an outside audience portraying an image of full, or arguably better, recovery after Haiyan. This attempt at 'happy-washing' masks the ongoing suffering of many communities still displaced and living in poor conditions. It conforms to the Haiyan narrative of resilience and exploits stereotypes of Filipinos as fun-loving people with slogans such as 'it's more fun in the Philippines' and 'we go the extra smile'. The romantic narrative of how Filipinos can still be among the happiest people in the world is effective given how disasters are frequent life experiences in the country (Bankoff 2007). Happy-washing, therefore, can be pernicious and ultimately counterproductive for long-term and inclusive post-disaster recovery (Su, Mangada, and Turalba 2018). 
Grand narratives shape the design of humanitarian responses and subsequent mobilisation of national and global resources for rebuilding. There is a risk that accounts of mutual aid, resourcefulness or local ingenuity, and self-reliance are mythologised and eventually ossified as 'truths' in the aftermath of disasters which can then inform long-term national and global disaster resilience programming. Haiyan represents a pivotal case because like other crises it offers opportunities for global learning given the collection of actors and resources mobilised by this disaster. Oxfam $(2013,7)$ observed that 'the world's immediate response to Haiyan has been generous - certainly when compared to the numerous other humanitarian crises that struggle for international attention'. Hence, it is all the more imperative to ensure that survival myths from this one case are scrutinised to strengthen global humanitarian and development agendas around disasters and increasingly in the face of extreme weather due to climate change.

\section{Myths of survival post-Typhoon haiyan}

National media and international humanitarian coverage of post-disaster recovery strongly drew upon narratives of survival and emphasised representations of communities joining together against all odds. International media coverage of the disaster notably including the 'celebrity' CNN reporter Anderson Cooper, similarly reproduced references to the inherent resilience of Filipinos in the aftermath of Haiyan (Macaraig 2013; Su and Mangada 2016; Sherwood et al. 2015). This specific approach, however, was in aid of silencing criticism for inadequate risk reduction and preparedness as well as slow response by the government. One study documented this shift:

President Aquino asked the media to give 'greater accuracy in reports' after the international media highlighted disorganized relief and recovery operations. The government said that the media has a 'role to uplift the spirits of the Filipino people - to find stories of resilience ...' instead of focusing on missing and slow search and rescue and relief and recovery. After this request, media outfits featured more stories about the 'very real and human face' and features that 'move others to action' (IBON Foundation, Inc. 2015, 55).

Stories of resilience and survival then became the predominant and enduring theme on how post-Haiyan was being represented nationally and internationally. Such representations took over all other post-disaster experiences and mythologised the Haiyan disaster by distilling it into a single script.

\section{Data and methods}

Our analysis is informed by our two separate but overlapping case study research projects. Case study research provides in-depth descriptions of a 
process within a bounded system or setting (Creswell 2007). It is a method that gathers different forms of data (Yin 2012). This type of research is particularly suited for studying disasters because it allows for the investigation of a phenomenon/a from multiple units, layers, and dimensions of analysis. The first research project involved field trips between January and April 2015, and April and May 2016, to Metro Manila and two provinces in the Eastern Visayas region: Tacloban City, Leyte; and Guiuan, Eastern Samar. In total, there were twenty-six in-depth interviews with nineteen women and seven men who represented different government, local and international NGOs, and local academics. Secondary literature included official snapshots and monitoring reports by governmental, non-governmental, and international humanitarian organisations. Moreover, secondary survey data on the conditions and experiences of displaced families and communities in Eastern Visayas in the aftermath of Haiyan were used to corroborate and add depth to the interview findings.

The second research project was designed as a mixed-methods study utilising qualitative and quantitative tools including generating primary survey data. Unlike the first research project, this project drew from extended field research of seven months over three periods undertaken between February 2015 and February 2017. The research site was exclusively in Tacloban City and primarily focused on the household as the unit of analysis. The study employed systematic random sampling of those who stayed or eventually returned to their original locations within three years of Haiyan's occurrence. It yielded a total of 465 short household surveys across three coastal barangays (villages). The households were categorised into single or dual-headed households with either female or male heads of households. Our data compared male and female heads of households according to who was considered the main income earner and a parent. Single-headed households meant either unmarried, separated, or widowed. Dual-headed households were defined as households that had both a male and female adult resident, often married or in a relationship. We note that culturally, it is still common for the man to be considered as the head of household even if women may contribute a majority of the household income, and this is partially reflected in the larger sample size for male breadwinners in dual-headed households.

The households were further classified into income groups of lower, middle, or upper class. Building on Ong's $(2015,63)$ categorisation, the upper class were considered as the landed elite, total income of over 50,000 pesos a month, with undergraduate degrees, white-collar occupations, and houses located in exclusive subdivisions. The middle class are seen as people earning between 15,001 to 50,000 pesos a month, with college-level educations, occupations in skilled and technical jobs, and houses in permanent or semipermanent conditions in mixed neighbourhoods. The lower-class income 
group are people who make less than 15,000 pesos a month, with high school or elementary educations, occupations in unskilled labour, and who live in semi-permanent and temporary homes. In the Philippines, middle and lower-class households are more susceptible to external shocks like disasters because they lack the economic safety nets and limited access to a wider range of resources to withstand crises (Ong 2015).

By combining our two projects, particularly through the triangulation of our multiple sources of data, we were able to separate the myths from the everyday and complex realities in the aftermath of a rapid-onset catastrophe. Collaboration represented an opportunity to enhance the rigour of our individual data collection and analysis. We argue that our collaboration generated an even more robust account of the narratives as well as patterns occurring across the household, community, and state levels. The joining of the micro-level household data with more macro-level analysis from government and NGO staff workers helps to provide a more comprehensive multiscalar view of post-disaster settings in relation to a broader politics of post-disaster response. Our dialogues as research collaborators form part of our research ethics in terms of checking our respective positionality - each acknowledging the limitations of our research standpoint and varying individual privileges to which we had to attend while conducting our research. Lastly, collaboration opened a space to reflect on our shared field experiences, which although marked by differing insider and outsider perspectives were nonetheless bounded within the same temporal and spatial interactions afforded by Tacloban City.

We now turn to the three myths using the case of post-Typhoon Haiyan disaster response and recovery in the Philippines.

\section{The myth of bayanihan and mutual assistance}

When Haiyan was about to make landfall, President Benigno Aquino III called on all Filipinos to practice bayanihan noting 'Alam nating walang bagyong maaaring magpaluhod sa Pilipino kung tayo'y magbabayanihan, (No storm will make the Filipino get down on his [sic] knees as long as we help each other)' (Cupin 2013). Bayanihan is a Filipino word that indicates collective cooperation, known as the 'ancient Filipino custom ... of group work' (Ang $1979,91)$ and 'toiling on another's behalf and assuming another's burden' (Bankoff 2007, 26). Media, government officials, international aid agencies, and some survivors themselves perpetuated the myth of mutual help by frequently referencing the resilience of communities and citing bayanihan in relation to the recovery efforts (for selected examples, see Gawad Kalinga 2013; Obordo 2013; Tan 2013; Nordenskiöld 2014; Viray 2014; Castaneda 2015; FAO 2015; GMA News Online 2013). President Barack Obama assured 


\section{Reported frequency of bayanihan among respondents before Typhoon Haiyan}

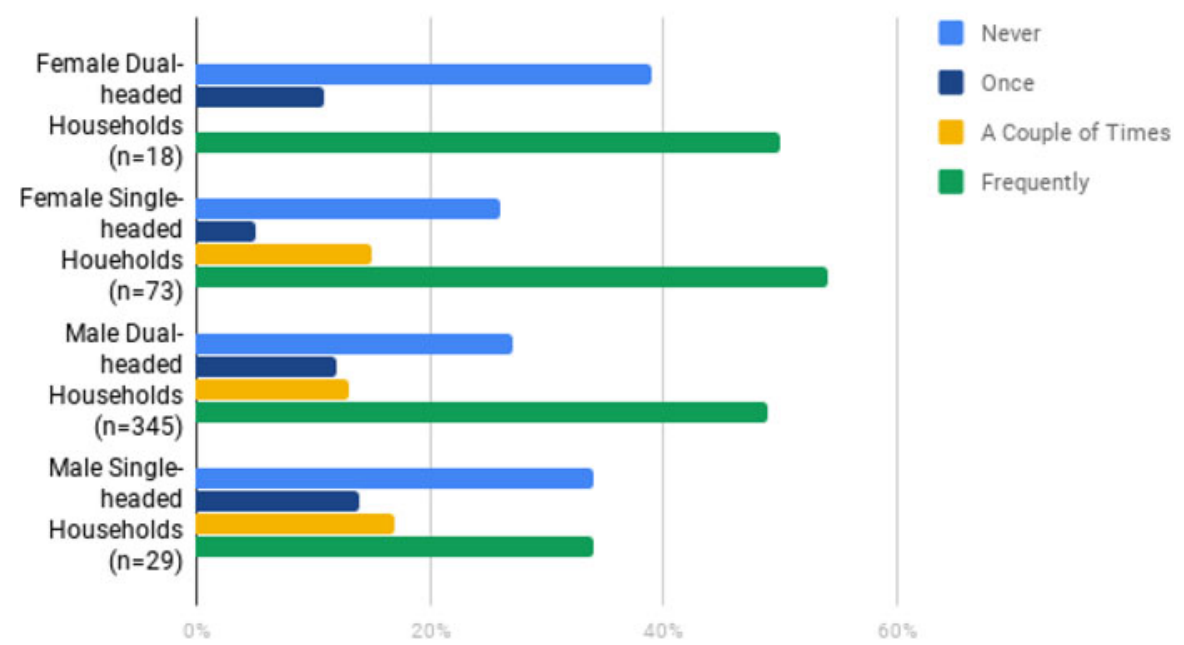

Figure 1. Bayanihan for Dual Headed Households vs Single Headed Households.

the people that despite the 'loss of life and extensive damage done by Super Typhoon Yolanda', he was 'confident that the spirit of Bayanihan will see [the Philippine people] through this tragedy' (White House 2013). Bayanihan then was being articulated not just as a form of collective action but a survival response inherent among Filipinos.

Our findings suggest that while the spirit of bayanihan existed, mutual assistance and other forms of bayanihan were brief experiences in the urban context of Tacloban City. In the case of Tacloban, of our 465 total respondents, 73 per cent said they witnessed bayanihan and the remainder said they did not. Among those who reported bayanihan, 47 per cent noted that it lasted from one week to a month, while 12 per cent said less than one week. Furthermore, our survey revealed that the temporal experience of bayanihan was also shaped by gender differences. When respondents were asked 'Before Yolanda [Haiyan], how often did your household join together with others in the barangay to address a common issue?', approximately 50 per cent in both female and male dual-headed households reported coming together frequently (see Figure 1). Yet for single-headed households, we observed that 54 per cent of female heads reported coming together frequently whereas only 34 per cent of their male counterparts reported doing so.

We interpret this difference through prevailing gender norms and expectations between female and male heads of household, notably based on their differing caregiving and protection demands with which they are faced. First, female single-headed households are more vulnerable to threats of sexual and gender-based violence because they do not have a male protector (Bradshaw 2015; Cupples 2007). As such, it is in their best interest to invest 


\section{Bayanihan as self-interest and not community altruism}

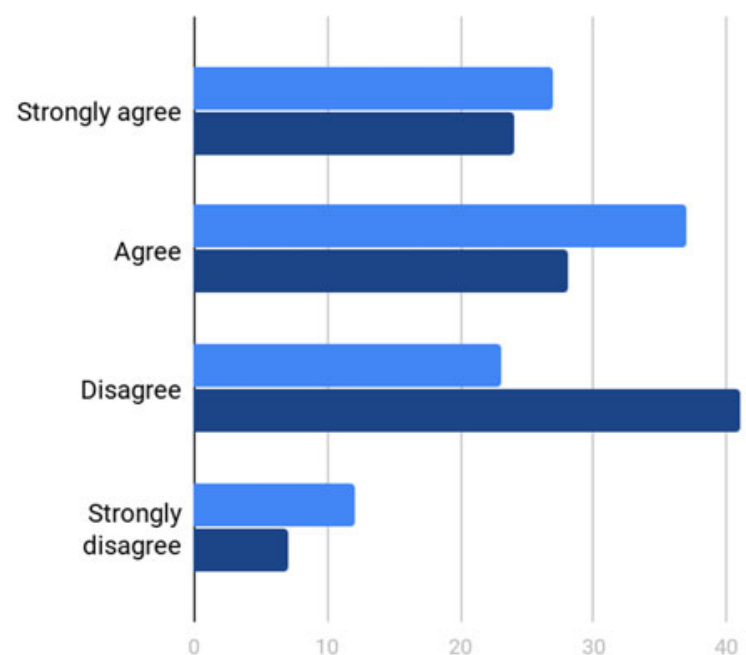

Female Single Headed Households

Male Single Headed Households

Figure 2. Reported motivation behind bayanihan according to male and female heads of household.

in social networks and practices such as pakikisama (reciprocity) and bayanihan. Second, they are also most in need of mutual assistance for everything, given the barriers to accessing post-disaster relief in the immediate aftermath. Male heads of household may take part in certain types of unpaid mutual assistance but are selective regarding which tasks they perform. This is because mutual assistance is undertaken insofar as it preserves their masculine identity of protector and breadwinner. For example, queuing for relief or seeking assistance was viewed as feminising and therefore undermines masculinity because it does not conform to the traditional image of men as providers (Novales 2014). Consequently, women filled in for relief shortages by finding alternative income sources for their households and in general were the ones who incurred heavy debts. Even in cases of dual-headed households, the men were reportedly 'too shy to borrow money' (Novales $2014,41)$. This gendered pattern corroborates broader research in the aftermath of Haiyan and helps us consider the distinct vulnerabilities of, and resources available to, women in single-headed households (UNFPA 2015).

Figure 2 illustrates that in terms of bayanihan, community well-being was secondary or served as a 'positive' side-effect to securing self-interest or family welfare in the immediate aftermath of the disaster. Most respondents believed that bayanihan is driven more by a sense of familial or clan interests rather than the altruistic promotion of community welfare. This fine distinction matters again in challenging the romanticisation of Haiyan-affected communities. That is, mutual assistance did not always equate to mutual trust. Indeed, our data also suggest that more female single-headed 
households believed that self-interest drives bayanihan than male singleheaded households (see Figure 2). Our male respondents were more likely to disagree that bayanihan is a promotion of self-interest. This is perhaps because these men were also the ones reporting bayanihan as looting together and clearing up debris after the disaster - masculine activities that are collectively done and visibly in the 'public sphere'.

Women have specific motivations to be sceptical of relying upon community altruism in the broader post-Haiyan context because reports of sexual and gender-based violence, especially in displacement sites, also ensued as the crisis unfolded (Tanyag 2018; UNFPA 2015). For example, as one informant reported, 'in the case of married women, they would rather keep the incident to themselves than tell their husbands to lessen or avoid conflict in the community' (personal interview, female NGO representative, Tacloban City, 23 February 2015). Yet, research has also shown that women keep the peace in highly fragile situations such as in the aftermath of disasters by maintaining their silence (Mangada 2016, 104). Among the forms of violence women and girls in Tacloban distinctly faced were intimate-partner abuse, rape, sexual violence, and prostitution (UNFPA 2015; Tanyag 2018). These occurred within their communities which meant that victims likely knew their perpetrators as neighbours or intimately as family members thereby making it extremely difficult and insecure to report the violence in a context of protracted displacement and due to insufficient protection mechanisms in place (Tanyag 2018, 575). In the face of disasters, survival myths that romanticise the community tend to mask violence and insecurities perpetrated from within (Smyth and Sweetman 2015). Broadly, our post-Haiyan findings corroborate research by Davis and Alexander (2016) which found that while the short-term reactions to sudden onset disasters can lead to increased social cohesion, in many cases the longer-term consequences are worsened social tensions and further divided societies.

\section{The myth of self-recovery and 'resourcefulness"}

Another commonly celebrated phenomenon after Haiyan was self-recovery efforts or self-led recovery. Self-recovery was the main focus for shelter organisations that gave small cash assistance as well as shelter repair kits to affected households to help them rebuild their homes by themselves. While the term self-recovery was mainly meant to be used in the context of shelter assistance within the post-Haiyan response, it quickly became an all-encompassing term for recovery and was often celebrated as a positive and resilient attribute among Haiyan-affected people. As the IASC Humanitarian Evaluation of the Typhoon Haiyan Response observed in October 2014 (eleven months after the typhoon), '[t]he response was characterised by the 
rapid self-recovery of the Filipino people who, within days, mostly returned home and were rebuilding at least makeshift shelter and seeking to rebuild their livelihoods, though often via use of high cost credit' (Hanley et al. 2014, vi). Self-recovery through high-cost credit is a negative coping mechanism that is unsustainable and damaging to the household in the long-term because it risks putting households in debt. Yet, high-cost credit is one of the only financial resources available to poor survivors during these critical times when they do not have personal savings or access to construction materials to rebuild their homes. This begs the question on the quality of recovery and who among household members bears the cost of long-term rebuilding when a family becomes buried in debt.

Resourcefulness is gendered. Self-recovery extended at the community level reveals that gender roles played an important part in defining who among the community were expected to bear the burden of resourcefulness. A positive example is manifested in the case of new mothers. The stress of the disaster, compounded in some cases by the loss of their husband, led them to have difficulty lactating. Women had to rely on other lactating mothers or resort to using poor substitutes such as excess water from boiled rice. According to a male NGO worker in Tacloban City, 'we heard stories and this was around the first three months after the storm, in the evacuation camps, many lactating mothers breastfed other infants' (personal interview, Tacloban City, 26 February 2015). Women's resourcefulness in this context demonstrated the impact of the disaster in transforming breastfeeding as a communal effort.

The expectation that women will make do with whatever is available, however, can exacerbate the physical and emotional strains they experience after a disaster largely because of intensified care obligations (Mangada 2016; Tanyag 2018). The myth of self-recovery is that it valorises the capacity of households to not just overcome the daily struggles of post-disaster survival but that these people are even able to 'thrive', 'innovate', or take initiatives in stretching available resources. Yet, this is done by erasing all the gendered sacrifices involved in rising up to the humanitarian narrative of resilience. For example, we found in the case of Tacloban City that despite the devastation, social welfare and community work were grossly undervalued. Our informants expressed that this type of frontline labour is integral to post-disaster recovery yet is done mostly by women and primarily on a voluntary basis:

At the barangay level, you can already see how community care work is devalued. Most of the jobs and services are staffed by volunteers. The work they do is not taken seriously in terms of giving them adequate training and remuneration (personal interview, female informant, Tacloban City, 23 February 2015).

Even worse, the women volunteers often have to use their own personal resources in performing their jobs. Under the myth of survival, this is coded 
as a positive aspect because it adds 'proof' to how resources are always plentiful and renewing among communities:

Transformative programs require so many resources and funding ... and yet many social services are on a voluntary-basis. If we get paid, we still shell out our own private time and money (personal interview, female city population officer, Tacloban City, 24 February 2015).

Finally, narratives of self-recovery and resourcefulness aid in legitimising state cutbacks or shortages on social welfare, particularly after a disaster, because frontline workers have been filling in the gaps even before the crisis:

They tell us there is not enough money available. That amount in my many years working as the city social welfare officer since 2010, that was the lowest budget we were given [after Haiyan]. How can that amount be enough for the whole year? We provide food and basic amenities here, pay utilities too. To survive, I would normally use my personal money just so we could all eat here. Come to think of it, that is really normal for government employees at low levels like us, we end up covering so many things with our own money (personal interview, female city social welfare officer, Tacloban City, 26 February 2015).

The above female informant worked for a women's and girls' crisis shelter where victims of domestic violence, rape, and sexual violence received support. At its extreme, therefore, survival myths can further dehumanise victims of sexual and gender-based violence, and the care workers that make personal sacrifices in order to protect their well-being.

\section{The myth of remittances-driven post-disaster survival}

In times of disasters and crises, a growing body of research has started to focus on the role of global households and remittances (Le De et al. 2015; Mohapatra, Joseph, and Ratha 2012; Fagen 2006; Deshingkar and Aheeyar 2006). Safri and Graham $(2010,107)$ define the global household as 'comprising the people who migrate, plus the people who are born into or otherwise incorporated into the immigrant household (e.g., through marriage or cohabitation), plus the people left behind, including new entrants to the home-country household.' Further, the global household is maintained by 'ties of economic and emotional interdependence' despite and because of geographic dispersion (107). Global households are important sites where macro-level economic processes take shape and they are integral to the reproduction of a neoliberal global political economy (Safri and Graham 2010; Tanyag 2017). They are increasingly relevant in understanding the global dimensions to post-disaster response and recovery.

It is commonly asserted that 'social capital is the capital of the poor' because it is believed that while poor people may not have material assets, they can 
generally rely on kin and social networks to protect themselves against risks and shocks (Eadie and Su 2018). But in the event of an extreme disaster, such as Haiyan, a household's core social network within the same geographic location may be equally affected, if not worse off. Households then need to rely on weaker or less familiar ties outside of their immediate community. Because of a long history of labour migration in the country, safety nets for many Filipino families may be available through the leveraging of global households in the form of remittances from overseas Filipino workers (OFWs).

Remittances constitute the largest type of financial flow to fragile contexts followed by official development assistance and then foreign direct investments (OECD 2016, 17). In the case of the Haiyan response, the IASC Humanitarian Evaluation report concluded that 'the diaspora played possibly the most direct and important role for many affected communities. In a year-on-year comparison, remittances to the Philippines rose by $\$ 600$ million in the first three months following Haiyan' (Hanley et al. 2014, 19). Indeed, as a male informant pointed out, 'remittances by migrants - local and international - have been crucial to disaster relief and recovery'. He added further that 'in the case of Tacloban, relatives were the first responders to victims' (personal interview, Quezon City, 3 February 2015). The surge of remittances after the disaster is to be expected given that the Philippines was the third largest recipient of remittances in the world in 2017 (KNOMAD 2016).

Remittances on their own cannot transform the pre-existing structural inequalities that compound the impacts of a disaster; they mitigate them. Our findings raise caution to overstating the importance and contribution of remittances to post-disaster recovery. Unlike long-term development assistance and investments in social welfare, they typically augment household daily care provisioning and rely on the assumption of unending altruism of mostly women migrant workers (Tanyag 2017). Overseas labour migration is also uneven throughout the different regions of the Philippines (Philippine Statistics Authority 2014). As in other parts of the world, class and genderbased inequalities structure access to labour migration, and the mileage from remittances are shaped by whether they are sent by low or high-skilled labourers in a global economy. High-skilled labour migration requires significant financial, social, and cultural capital to comply with the prerequisites for skilled migration overseas - ranging from educational costs, and visa application and recruitment agency fees. If a breadwinner from a lower-class household manages to fulfill the migration requirements, this comes at the cost of their family incurring debts.

The study by Le De et al. (2015) on remittances and post-disaster recovery in Samoa demonstrates how the lower class have no, or very limited, ability to receive remittances, or to turn their access to remittances into longterm financial assistance for recovery. Remittances reinforce pre-existing 
socio-economic inequalities as well as create new ones. We find similarities in our research in the Haiyan aftermath. Of the 465 households in the study, 95 were classified as middle class and 370 were classified as lower class. While 49 per cent of middle-class households reported having an OFW or migrant abroad, only 18 per cent of lower-class households reported the same. This means that 82 per cent of the lower-class households in the study did not have an OFW or migrant and thus did not have pre-existing access to remittances. Moreover, access did not automatically equate to receiving remittances. Among households with OFWs, when asked if they received remittances in the aftermath of Haiyan, 21 per cent of middle-class households said yes compared to 2.7 per cent among lower-class households. This suggests that among our respondents, remittances served to amplify preexisting economic inequalities and also contributed to wider unequal recovery after Haiyan. As a female informant based in the remote town of Guiuan, Samar, stated:

OFWs and private remittances contribute to the unequal recovery after the storm. So you can see concrete houses amidst nipa huts. Those with relatives working overseas received assistance to rebuild including to start a new livelihood (personal interview, representative of INGO, 24 February 2015).

Hence, remittances are symptomatic of how the ability to survive is grossly unequal. Haiyan-affected households with limited or no access to remittances were not able to rebuild fully. They are thus also more exposed and vulnerable when the next typhoon strikes. This point is important because the main provinces of the Eastern Visayas region were found to have the largest proportion of individuals with social vulnerabilities and special needs, 'possibly [as] a result of the higher impact from the typhoon, continued displacement and consolidation of households as well as pre-existing economic vulnerability' (DSWD et al. 2014, 18).

The pressure to secure remittances for one's family is gendered too for a country with a highly feminised, low-skilled labour export. The Haiyan case demonstrates clearly among communities that migrating overseas or to bigger cities within the Philippines can bring back much needed remittances to fund post-disaster recovery. This in turn can place immense expectations on women to cross borders thereby exposing them to human trafficking and sex work as stepping stones to migrate. As one male NGO representative emphasised, 'when the military planes came to evacuate whole towns to Cebu, it was a real mass exodus. Many just boarded with no clear idea of where they were going after Cebu and whether or how they will survive especially financially. People were literally hauled out of Tacloban' (personal interview, Tacloban City, 26 February 2015). He added further, 'this was a critical juncture for trafficking and high vulnerability of women to take on whatever "job" they can get so they and their dependents can survive... Some would probably go to 
relatives out of Visayas but there would still be women who likely ended up in Pasay or Angeles [in sex tourist spots]'.

These dark sides to remittances-driven recovery in the aftermath of Haiyan need to be fully accounted in the reproduction of stories celebrating the Filipino diaspora. At a time of escalating disaster risks for the Philippines and globally as a result of climate change, the Filipino diaspora and remittances will certainly play prominent and permanent roles in post-disaster recovery. We need to pay attention to how myth-making around remittances operates most effectively in times of disasters to conceal inequalities at national and global levels.

\section{Conclusion}

Alongside the death and devastation from the Typhoon Haiyan crisis, the construction and subsequent proliferation of survival myths were integral in normalising many of the failures, tensions, and harms resulting not only due to the typhoon but also through the post-disaster response. In this article, we critically examined three survival myths in the aftermath of Typhoon Haiyan within the specific locality of Tacloban City, Philippines. The disaster response relied upon and proliferated narratives on the local culture of bayanihan, the endless resourcefulness of Filipinos in times of crisis, and the power of remittances-driven survival. However, focusing our analysis on gender and class inequalities, we expose these narratives as integrally part of legitimising contemporary post-disaster recovery in the Philippines. The findings from our research underscore the importance of interrogating how similar survival myths are being globalised in disaster governance at the expense of forging substantive gender equality and social transformation in postdisaster settings.

Survival myths are underpinned by, and help perpetuate, gender and class-based inequalities beginning at the household and globally. Feministinformed analysis must be mainstreamed as part of the toolkits deployed in researching disaster risks and responses. This means that in practice we do not neglect the household as a vital post-disaster unit for survival. Interventions must penetrate through the gendered division of labour that condition household dynamics and the full costs of coping mechanisms post-disaster. Household dynamics have indirect impacts on the quality and extent of community-level cooperation and competition. Post-disaster recovery of households and communities is shaped by pre-existing access or distribution of resources from material to social capital, and along gender and class lines. The over-deployment of survival myths by international and national humanitarian actors may serve a short-term purpose of consolidating affected populations and uplifting morale. However, their global and 
national implications are in the erasure of where things went wrong, the foreclosure of productive discussions of what can be done better, and importantly, mechanisms for communities to make governments and international organisations responsible for protection.

Critical and feminist research has a role to play in ensuring that grand narratives of survival do not hinder in exacting accountability from the state and international community in addressing gendered inequalities. When the debris has been cleared and after the disaster has passed, mechanisms must be in place to hold state and non-state actors accountable for remedying the unintended consequences of a disaster response before the next crisis occurs. Adapting to ever more precarious conditions in the face of climate change requires developing intersectional analytical lenses, multi-scalar capacities, and the progressive bridging between immediate crisis response and long-term, inclusive development.

\section{Acknowledgments}

We would like to thank three anonymous reviewers for their instructive feedback and the editor, for a supportive publication experience. We are also very grateful to Professor Ladylyn Mangada whose generosity, insights and mentoring facilitated the beginning of our collaboration.

\section{Disclosure statement}

No potential conflict of interest was reported by the authors.

\section{Funding}

International Development Research Centre; Social Sciences and Humanities Research Council of Canada.

\section{Notes on contributors}

Yvonne Su is a Ph.D. candidate in political science and international development at the University of Guelph in Canada. Her research examines poverty and inequality, climate change, resilience, and migration. Yvonne has published on climate change-induced displacement, mainstreaming climate change resilience into urban policy, applying the capabilities approach to the global governance of migration and post-disaster recovery in the Philippines. Her current research is on post-disaster recovery, remittances, social capital, and development in Southeast Asia.

Maria Tanyag is a Lecturer at the Department of International Relations at the Coral Bell School of Asia Pacific Affairs, Australian National University. She was a postdoctoral research fellow at the Monash University Centre for Gender, Peace and Security where she was also awarded her PhD in 2018. Maria's current research interest is in theorising 
how the standpoints of indigenous and internally displaced women reconceptualise climate change as an integrated global security, rights and development agenda.

\section{References}

Ang, Gertrudes R. 1979. "The Bayanihan Spirit: Dead or Alive?" Philippine Quarterly of Culture and Society 7 (1/2): 91-93.

Arora-Jonsson, Seema. 2011. "Virtue and Vulnerability: Discourses on Women, Gender and Climate Change." Global Environmental Change 21 (2): 744-751. doi:10.1016/j.gloenvcha. 2011.01.005.

Arora-Jonsson, Seema. 2014. "Forty Years of Gender Research and Environmental Policy: Where Do We Stand?" Women's Studies International Forum 47: 295-308. doi:10.1016/j. wsif.2014.02.009.

Bankoff, Greg. 2007. "Living with Risk; Coping with Disasters: Hazard as a Frequent Life Experience in the Philippines." Education about Asia 12 (2): 26-29.

Bradshaw, Sarah. 2015. "Engendering Development and Disasters." Disasters 39 (S1): S54-S75. doi:10.1111/disa.12111.

Brickell, Katherine, and Sylvia Chant. 2010. "The Unbearable Heaviness of Being': Reflections on Female Altruism in Cambodia, Philippines, the Gambia and Costa Rica." Progress in Development Studies 10 (2): 145-159. doi:10.1177/146499340901000204.

Castaneda, Dabet. 2015. "One Year after Yolanda: Leytenos Rebuild Homes, Communities through Bayanihan." Bulatat, 8 February. http://bulatlat.com/main/2015/02/08/one-yearafter-yolandaleytenos-rebuild-homes-communities-through-bayanihan/.

Cupin, Bea. 2013. "Aqunio: Yolanda 'Serious Threat,' Don't Take Chances." Rappler, 8 November. http://www.rappler.com/nation/43154-aquino-statement-yolanda.

Cupples, Julie. 2007. "Gender and Hurricane Mitch: Reconstructing Subjectivities after Disaster." Disasters 31 (2): 155-175. doi:10.1111/j.1467-7717.2007.01002.x.

Creswell, John. 2007. Qualitative Inquiry and Research Design: Choosing among Five Approaches. Thousand Oaks: Sage Publications.

Davis, lan, and David Alexander. 2016. and Recovery from Disaster. London: Routledge.

De La Rocha, Mercedes González. 2007. "The Construction of the Myth of Survival." Development and Change 38 (1): 45-66.

Department of Social Welfare and Development (DSWD), International Organization for Migration (IOM), Internal Displacement Monitoring Centre (IDMC), and SAS. 2014. The Evolving Picture of Displacement in the Wake of Typhoon Haiyan: An Evidence-Based Overview. May. http://www.iom.int/files/live/sites/iom/files/Country/docs/The-EvolvingPicture-of-Displacement-in-the-Wake-of-Typhoon-Haiyan.pdf.

Deshingkar, Priya, and M. M. M. Aheeyar. 2006. "Remittances in Crisis: Sri Lanka after the Tsunami." HPG Background Paper. London: Overseas Development Institute.

Doss, Cheryl, Ruth Meinzen-Dick, Agnes Quisumbing, and Sophie Theis. 2018. "Women in Agriculture: Four Myths." Global Food Security 16: 69-74. doi:10.1016/j.gfs.2017.10.001.

Eadie, Pauline, and Yvonne Su. 2018. "Post-Disaster Social Capital: Trust, Equity, Bayanihan and Typhoon Yolanda." Disaster Prevention and Management: An International Journal 27 (3): 334-345. doi:10.1108/DPM-02-2018-0060.

Eckstein, David, Vera Künzel, and Laura Schäfer. 2017. Global Climate Risk Index 2018. Bonn; Berlin: GermanWatch.

Elson, Diane. 2010. "Gender and the Global Economic Crisis in Developing Countries: A Framework for Analysis." Gender and Development 18 (2): 201-212. doi:10.1080/ 13552074.2010.491321. 
Enarson, Elaine. 1998. “Through Women's Eyes: A Gendered Research Agenda for Disaster Social Science." Disasters 22 (2): 157-173. doi:10.1111/1467-7717.00083.

Enarson, Elaine. 2012. Women Confronting Natural Disaster: From Vulnerability to Resilience. Boulder: Lynne Rienner Publishers.

Fagen, Patricia. 2006. "Remittances in Crises: A Haiti Case Study." HPG Background Paper. London: Overseas Development Institute.

Food and Agriculture Organization of the United Nations (FAO). 2015. "Typhoon Haiyan: Portraits of Resilience." Manila: FAO. http://www.fao.org/3/a-i5177e.pdf.

Gaillard, J. C., Andrew Gorman-Murray, and Maureen Fordham. 2017. "Sexual and Gender Minorities in Disaster." Gender, Place \& Culture 24 (1): 18-26. doi:10.1080/0966369X. 2016.1263438.

Gaillard, J. C., Kristinne Sanz, Benigno C. Balgos, Soledad Natalia M. Dalisay, Andrew Gorman-Murray, Fagalua Smith, and Vaito'a Toelupe. 2017. "Beyond Men and Women: A Critical Perspective on Gender and Disaster." Disasters 41 (3): 429--447. doi:10.1111/ disa.12209.

Kalinga, Gawad. 2013. "Breaking Barriers through Bayanihan: Typhoon Yolanda (Haiyan) Update as of Nov 19." 20 November. http://gk1world.com/breaking-barriers-throughbayanihan.

GMA News Online. 2013. "The Bayanihan Spirit Lives on in the Kapuso Community despite Yolanda." 13 December. http://www.gmanetwork.com/news/cbb/content/339680/thebayanihan-spirit-lives-on-in-the-kapuso-community-abroad-despite-yolanda/story/.

Guijt, Irene, and Meera Kaul Shah, eds. 1998. The Myth of Community: Gender Issues in Participatory Development. Bourton-on-Dunsmore: Intermediate Technology Publications.

Hanley, Teresa, Rusty Binas, Julian Murray, and Baltz Tribunalo. 2014. "IASC Inter-Agency Humanitarian Evaluation of the Typhoon Haiyan Response." New York: United Nations Office for Coordination of Humanitarian Affairs.

Horton, Lynn. 2012. "After the Earthquake: Gender Inequality and Transformation in PostDisaster Haiti." Gender and Development 20 (2): 295-308. doi:10.1080/13552074.2012. 693284.

IBON Foundation, Inc. 2015. Disaster upon Disaster: Lessons beyond Yolanda. Quezon City: IBON Foundation, Inc. https://www.medico.de/fileadmin/user_upload/media/en/ Disaster_Upon_Disaster_Final.pdf.

Katz, Cindi. 2008. "Bad Elements: Katrina and the Scoured Landscape of Social Reproduction." Gender, Place \& Culture 15(1): 15-29. doi:10.1080/09663690701817485.

KNOMAD. 2016. "Migration and Remittances: Recent Developments and Outlook." Migration and Development Brief 29. April. http://www.knomad.org/publication/migration-and-development-brief-29.

Kothari, Uma. 2001. "Power, Knowledge and Social Control in Participatory Development." In Participation: The New Tyranny?, edited by Bill Cooke and Uma Kothari, 139-52. London: Zed Books.

Le De, L., J. C. Gaillard, W. Friesen, and F. Matautia Smith. 2015. "Remittances in the Face of Disasters: A Case Study of Rural Samoa." Environment, Development and Sustainability 17 (3): 653-672. doi:10.1007/s10668-014-9559-0.

Macaraig, Ayee. 2013. "Anderson Cooper: An Honor to Report on PH." Rappler, 22 November. https://www.rappler.com/move-ph/issues/disasters/typhoon-yolanda/44301anderson-cooper-reflections-haiyan-coverage.

Mangada, Ladylyn Lim. 2016. "Post-Haiyan Adaptation and Institutional Barriers to Women Survivors in Tacloban." Philippines Political Science Journal 37 (2): 94-110. 
Mohapatra, Sanket, George Joseph, and Dilip Ratha. 2012. "Remittances and Natural Disasters: Ex-Post Response and Contribution to Ex-Ante Preparedness." Environment, Development and Sustainability 14(3): 365-387. doi:10.1007/s10668-011-9330-8.

Nordenskiöld, Sofia Klemming. 2014. "One Year after Typhoon Haiyan: Resilience Rebuilds the Philippines." CNN, 7 November. https://www.cnn.com/2014/11/06/world/asia/philippines-typhoon-haiyan-one-year/index.html.

Novales, Clementine Louise. 2014. Haiyan Gender Snapshot: Leyte, Eastern Samar and Northern Cebu. Quezon City: Oxfam.

Obordo, Rachel. 2013. "Typhoon Haiyan won't keep us Filipinos down for long." The Guardian, 11 November. https://www.theguardian.com/commentisfree/2013/nov/10/ typhoon-haiyan-filipinos-come-back-fighting.

Ong, Jonathon Corpus. 2015. The Poverty of Television: The Mediation of Suffering in ClassDivided Philippines. London: Anthem Press.

Ong, Jonathan Corpus, Jaime Manuel Flores, and Pamela Combinido. 2015. Obliged to be Grateful: How Local Communities Experienced Humanitarian Actors in the Haiyan Response. Plan International. https://plan-international.org/publications/obliged-begrateful.

Organisation for Economic Co-operation and Development (OECD). 2016. States of Fragility 2016. Paris: OECD Publishing.

Oxfam. 2013. "Typhoon Haiyan: The Response So Far and Vital Lessons for the Philippines Recovery." Oxfam Briefing Note, 7 December. https://www.oxfam.de/system/files/ 20131206_typhoon-haiyan-philippines-response.pdf.

Oxfam. 2015. "Women after the Storm: Gender Issues in Yolanda Recovery and Rehabilitation." Report. Quezon City. http://library.pcw.gov.ph/sites/default/files/ women\%20after\%20the\%20storm.pdf.

Perera-Mubarak, Kamakshi N. 2013. "Positive Responses, Uneven Experiences: Intersections of Gender, Ethnicity, and Location in Post-Tsunami Sri Lanka." Gender, Place \& Culture 20 (5): 664-685. doi:10.1080/0966369X.2012.709828.

Philippine Statistics Authority. 2014. "2013 Survey of Overseas Filipinos." Philippine Statistics Authority. https://www.psa.gov.ph/content/2013-survey-overseas-filipinos.

Safri, Maliha, and Julie Graham. 2010. "The Global Household: Toward a Feminist Postcapitalist International Political Economy." Signs: Journal of Women in Culture and Society 36 (1): 99-125. doi:10.1086/652913.

Sherwood, Angela, Megan Bradley, Lorenza Rossi, Rufa Guiam, and Bradley Mellicker. 2015. Resolving Post-Disaster Displacement: Insights from the Philippines after Typhoon Haiyan (Yolanda). Geneva: IOM; Washington, DC: Brookings Institution.

Smyth, Ines, and Caroline Sweetman. 2015. "Introduction: Gender and Resilience." Gender and Development 23 (3): 405-414. doi:10.1080/13552074.2015.1113769.

Su, Yvonne, and Ladylyn Lim Mangada. 2016. "Bayanihan after Typhoon Haiyan: Are We Romanticising an Indigenous Coping Strategy?" Report, Humanitarian Practice Network, 10 August. http://odihpn.org/resources/bayanihan-after-typhoon-haiyan-are-we-romanticising-an-indigenous-coping-strategy/.

Su, Yvonne, and Ladylyn Lim Mangada. 2018. "A Tide That Does Not Lift All Boats: The Surge of Remittances in Post-Disaster Recovery in Tacloban City, Philippines." Critical Asian Studies 50 (1): 67-85. doi:10.1080/14672715.2017.1401935.

Su, Yvonne, Ladylyn Mangada, and Jessa Turalba. 2018. "Happy-Washing: How a 'Happiness Campaign' Hurts Disaster Survivors." New Mandala, 27 April. http://www. newmandala.org/happy-washing-happiness-campaign-hurts-disaster-survivors/. 
Tan, Kimberly Jane. 2013. "PNoy Calls for Bayanihan amid Yolanda Threat." GMA News Online, 7 November. http://www.gmanetwork.com/news/news/nation/334464/pnoycalls-for-bayanihan-amid-yolanda-threat/story/.

Tanyag, Maria. 2017. "Invisible Labor, Invisible Bodies: How the Global Political Economy Affects Reproductive Freedom in the Philippines." International Feminist Journal of Politics 19 (1): 39-54. doi:10.1080/14616742.2017.1289034.

Tanyag, Maria. 2018. "Resilience, Female Altruism, and Bodily Autonomy: Disaster-Induced Displacement in Post-Haiyan Philippines." Signs: Journal of Women in Culture and Society 43 (3): 563-585. doi:10.1086/695318.

United Nations Population Fund (UNFPA). 2015. State of World Population 2015: Shelter from the Storm: A Transformative Agenda for Women and Girls in a Crisis-Prone World. New York: UNFPA.

United Nations General Assembly (UNGA). 2016. Report of the Special Rapporteur on the Human Rights of Internally Displaced Persons on his Mission to the Philippines. Human Rights Council 32nd session, A/HRC/32/35/Add.3. 5 April. https://documents-dds-ny.un. org/doc/UNDOC/GEN/G16/068/60/PDF/G1606860.pdf?OpenElement.

Viray, Patricia Lourdes. 2014. "Roving Around: 'Bayanihan' Spirit in Yolanda-Hit Communities." The Philippine Star, 7 November. http://www.philstar.com/headlines/ 2014/11/07/1389140/roving-around-bayanihan-spirit-yolanda-hit-communities.

White House. 2013. "Statement by the President on Super Typhoon Haiyan/Yolanda." Office of the Press Secretary, 10 November.

Yin, Robert. 2012. Applications of Case Study Research, 3rd ed. Thousand Oaks: Sage. 